\title{
Correction to: Direct observation of procedural skills (DOPS) assessment in diagnostic gastroscopy: nationwide evidence of validity and competency development during training
}

\author{
Keith Siau ${ }^{1,2}$ - James Crossley ${ }^{3} \cdot$ Paul Dunckley $^{1,4} \cdot$ Gavin Johnson $^{1,5} \cdot$ Mark Feeney $^{1,6} \cdot$ Neil D. Hawkes $^{7}$. \\ Ian L. P. Beales ${ }^{8}$. The Joint Advisory Group on Gastrointestinal Endoscopy (JAG)
}

Published online: 1 April 2019

(c) The Author(s) 2019

\section{Correction to: Surgical Endoscopy} https://doi.org/10.1007/s00464-019-06737-7

The citation for Reference 22 should be replaced with:

Kumar NL, Kugener G, Perencevich ML, et al (2018) The SAFE-T assessment tool: derivation and validation of a web-based application for point-of-care evaluation of gastroenterology fellow performance in colonoscopy. Gastrointest Endosc 87(1):262-269

Publisher's Note Springer Nature remains neutral with regard to jurisdictional claims in published maps and institutional affiliations.

The original article can be found online at https://doi.org/10.1007/ s00464-019-06737-7.

Keith Siau

keith@siau.org

1 Joint Advisory Group on Gastrointestinal Endoscopy, Royal College of Physicians, London, UK

2 Medical and Dental Sciences, University of Birmingham, Birmingham, UK

3 Academic Unit of Medical Education, University of Sheffield, Sheffield, UK

4 Department of Gastroenterology, Gloucestershire Hospitals NHSFT, Gloucester, UK

5 Department of Gastroenterology, University College London Hospitals NHSFT, London, UK

6 Department of Gastroenterology, Torbay and South Devon NHS Foundation Trust, Torquay, UK

7 Department of Gastroenterology, Cwm Taf University Health Board, Llantrisant, UK

8 Department of Gastroenterology, Norfolk and Norwich University Hospital, Norwich, UK 